\title{
Application of the Internet of things in logistics information platform
}

\author{
Zhonghua Lu \\ Linyi University, Shandong, China \\ sduman@126.com
}

Key Words: Internet of things; RFID; logistics information platform; information system

ABSTRACT. This paper is aimed at discussing the Internet of things and RFID (radio frequency identification) technology to improve the informatization level of logistics information platform. Based on analyzing the functional demand of logistics information platform, a framework of logistics information system is constructed. Started from the logistics information collecting, the paper introduces the basic features and advantages of Internet of things, discusses the feasibility and ways of applying the Internet of things technology into logistics information platform.

\section{Internet of Things}

The Internet of things is an important part of a new generation of information technology. As the name suggests, the Internet of things is something connected to the Internet, which has two meanings as follows: on the one hand, the core and foundation of the Internet of things is still the Internet, a extended and expanded Internet based on the network; on the other hand, the client of it extended between any goods and goods, for information exchange and communication. In fact, the Internet of things is the network connecting objects and objects. Considering the intelligent recognition and pervasive computing technology widely used in network, the Internet of things is called the third wave of world information industry development, after the computer and the Internet.

The definition of the Internet of things is putting all items, in accordance with the contract agreement, connected to the Internet by the information sensing devices, such as laser scanner, radio frequency identification (RFID), infrared sensors, global positioning system (GPS) and so on, doing some information exchange and communications, to realize intelligent identification, location, tracking and monitoring and management.

The Internet of things can be divided into three layers: perception layer, network layer and application layer.

First of all, the perception layer is made up of all sorts of equipment with the ability of perception, which means connecting that equipment to the network by using several terminal such as the RFID, GPS, camera, sensors, electronic telescopes or artificially intelligent terminals, easy for monitoring the change of environment, information collection and access to the object in any place and any time.

In addition, network layer is composed of all kinds of networks, including the Internet, network, network management system and cloud computing platform and so on, which is the center of the Internet of things, responsible for the information transmission and data processing achieved by the perception layer.

The application layer is the interface between the Internet of things and the user, which combined with industry demand, to realize the intelligent application of Internet of things.

There are several key technologies in the Internet of things as follows:

1) Sensor technology, which is the key technology of computer application. As we know, most of the information processed by computer is the digital signal. The function of sensor equipment is exactly converting analog signals into digital signals.

2) RFID (Radio frequency identification), which is also a kind of sensor technology, as well as a comprehensive technology combined with radio frequency technology and embedded technology. RFID has a broad application prospect in automatic identification, logistics management. 
3) Embedded system, which is a complex technology combined with computer hardware and software technology, sensor technology, integrated circuit technology, electronic application technology and so on. After decades of evolution, the intelligent terminal products characterized by an embedded system are very popular. Embedded system has been changed people's life, at the same time, promoting the industrial production and the development of defense industry.

4) GPS (Global Position System), a perimeter circular orbit satellite navigation system, which can provide most of the earth's surface area with accurate location, speed and high precision of time standards.

\section{Logistics information platform}

Logistics is a complicated system touching on several aspects of social economical life. During the course of developing logistics industry, a very important job is to plan and develop the corresponding regional logistics information platform. What is called regional logistics information platform, refers to actually a universal information interchange platform through which we collect, classify, sift, store, analyze, evaluate, feedback, publish, manage the related information about regional logistics operation, logistics process and logistics management by applying computer, network, communication and something like that kind of information technology. The information platform is the critical base-technology which support the regional logistics development, it dose play an important role in integrating the regional logistics information resources, improving the informatization level of logistics, raising the efficiency of logistics, reducing logistics cost and so force.

In the specific logistics process, the collection of logistics data is very important. With the popularization of RFID (Radio Frequency Identification) technology, there is a fresh way to collect the processing data correctly together with high efficiency. Connecting RFID technology with logistics information platform, we can expand the scope of application and management of logistics information platform, improve the systematic integration of logistics resources and provide the integral service for the customers.

\section{Application of the Internet of things in logistics information platform}

The application field of the Internet of things is very broad, from daily family personal application to industrial automation application, even military counterterrorism, urban construction and transportation. At present, the Internet of things has been had preliminary application in many aspects such as the logistics information platform. In the logistics information platform, there are several typical applications, including wireless remote automatic meter reading system, urban traffic system, storehouse monitoring system etc. IOT is built on the basis of the Internet technology, and will track and monitor the real-time logistics information. Taking the transport management module as an example, this is a part of the Internet of things. The Internet of vehicles is the vehicle dynamic system refers to the car and car, car and road, interact with people, cars and sensing devices, for mobile communications network communication with the public. It can realize information sharing by car and car, car and people, vehicles and road connectivity, collecting information of vehicle, road and environment, at the same time, processing calculating and sharing multi-source collection on information network platform. Additional, it will provide effective guidance and supervision according to the different functional requirements of vehicle and offer professional multimedia and application services of mobile Internet.

As a part of the Internet of things, RFID is a non-contact auto-recognition technology. It recognizes the object through radio frequency signal and can track the goods and exchange data quickly. In recognition work, there is no man needed, it can work in adverse circumstances. RFID technology can recognize high speed moving object and recognize several labels at the same time with easy operation. It benefits for the accomplishment of ERP (enterprise resource planning) and CRM (customer relationship management) business systems and can improve the business and commercial model greatly. Recently, RFID got a great deal of attention because of long-distance readability and high capacity. RFID not only help logistics enterprises improve the efficiency of goods and information management, but connect logistics enterprises with manufacturing 
enterprises. So that we can receive the feedback information, control the demand information, optimize the whole supply chain, and improve the operative efficiency of the logistics information platform better. Adopting long-range e-tag, setting up antenna near the door, the activities such as warehousing, delivering and checking will be completed with hand readers.

\section{Challenge and opportunity}

As we know, the Internet of things is called the third wave of world information industry after the computer and the Internet. In the near future, the Internet of things will be large-scale popularization, as a high-tech market, forming the public management and service, enterprise, individual and family application three major market segments. The most serious challenge the Internet of things encountered in the process of development lies in its standard. The development of the Internet of things must involve communication technology standards. However, how to unify all kinds of communication protocol standard is a very long process. Chinese RFID standards have been mentioned for many years, but still not unified, which is exactly one of the key factors to restrict the development of Chinese RFID. On the other hand, the Internet of things have been faced many technical challenges, mainly including artificial intelligence, image recognition, cloud computing and other technical problems. The biggest problem is from the artificial intelligence technology and its applications. Since starting, artificial intelligence technology has not been made any breakthrough in progress and is far from the requirements of the Internet of things. The "next big thing" is the Internet of Things, a world of networked devices equipped with sensors and radio-frequency identification aimed at interconnecting all things electronic to make them more intelligent and programmable. About 50 billion machines and devices could be linked by 2020, according to Cisco Systems, a leader in the IoT movement.

On the architecture aspect, the logistics information platform includes physical level, technical level, data level, functional level and service level. During the course of developing the logistics information platform, the universal standard-planning oriented to the information and the information source interface should be done well at first, it is critical to ensure the operation of information platform. The information platform based on GIS is the core technology to realize the bottom support of the system effectively. The middle-ware development technology centered on the CORBA provides great convenience for solving the operative problems of every kinds of software under the distributed and heterogeneous circumstances. The emphasis of the integration of RFID technology and information platform is on the inventory management. From the general framework of information platform to the connection of sub-system, until to the intelligent read-and-write system, the functional requirement of logistics information platform is satisfied.

\section{References}

[1] ZHAO Zhen, "Research on the planning of the provincial information platform of logistics," Computre Engineering \& Science, Science press, Beijing, vol.30, May 2008, pp. 138-141.

[2] HE Jie, LI Xuhong, and MAO Haijun, "Analysis on structure scheme of the provincial information platform of logistics," Communication Technology, Science press, Beijing, vol.23, June 2003, pp. 72-74.

[3] WANG Xiaokun, YANG Dongyuan, and ZHANG Jin, "Study on function orientation and structure of logistics public information platform," Journal of Kunming University of Science and Technology (Science and technology), University of kunming science and technology, Kunming, vol.33, April 2008, pp. 137-141.

[4] XU Wei, ZHAO Songzheng, and JIANG Weiyang, "Research on system structure of regional logistics information platform," Journal of Information, Science press, Beijing, vol.15, July 2008, pp.9-12. 
[5] LI Yuming, LIU Shanzhong, and LI Xuhong, "Framework analysis of regional logistics information platform," Journal of Henan University of Science and Technology, University of henan science and technology, Zhengzhou, vol.25, Jan. 2008, pp. 65-68.

[6] ZHAO Zhengfen, CUI Nanfang, and CHEN Rongqiu, "Study on function orientation and operation mechanism of regional logistics information platform," Logistics Technology, Science press, vol.6, April 2004, pp. 63-66.

[7] Schumann,fosef, "TIRLS-Leader in radio frequency identification technology,"Texas Instruments Technical Journal, Texas, vol.55, June 1993,pp.76-80. 